Article

\title{
Application of Particle Swarm Optimization in the Design of an ICT High-Voltage Power Supply with Dummy Primary Winding
}

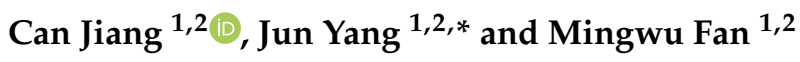 \\ 1 State Key Laboratory of Advanced Electromagnetic Engineering and Technology, Huazhong University of \\ Science and Technology, Wuhan 430074, China; jiangcan@hust.edu.cn (C.J.); fanmw@mail.hust.edu.cn (M.F.) \\ 2 School of Electrical and Electronic Engineering, Huazhong University of Science and Technology, \\ Wuhan 430074, China \\ * Correspondence: jyang@hust.edu.cn
}

check for updates

Citation: Jiang, C.; Yang, J.; Fan, M. Application of Particle Swarm Optimization in the Design of an ICT High-Voltage Power Supply with Dummy Primary Winding. Electronics 2021, 10, 1866. https://doi.org/ 10.3390 /electronics10151866

Academic Editors: Tamás Orosz, David Pánek, Anton Rassõlkin and Miklos Kuczmann

Received: 2 July 2021

Accepted: 30 July 2021

Published: 3 August 2021

Publisher's Note: MDPI stays neutral with regard to jurisdictional claims in published maps and institutional affiliations.

Copyright: (c) 2021 by the authors. Licensee MDPI, Basel, Switzerland. This article is an open access article distributed under the terms and conditions of the Creative Commons Attribution (CC BY) license (https:// creativecommons.org/licenses/by/ $4.0 /)$.

\begin{abstract}
The distribution of disk output voltage is a key factor for the design of an insulated core transformer (ICT) high-voltage power supply. The development of an ICT involves the design and optimization of many parameters, which greatly affect the uniformity of disk output voltage. A new ICT structure with dummy primary windings can compensate for the disk output voltage, which aims to improve uniformity. In this work, an optimization method based on a particle swarm optimization (PSO) algorithm was used to optimize the design parameters of an ICT with dummy primary windings. It achieved an optimal uniformity of disk output voltage and load regulation. The design parameters, including the number of secondary winding turns and the compensation capacitance, were optimized based on the finite-element method (FEM) and Simulink circuit simulation. The results show that the maximum non-uniformity of the disk output voltage is reduced from $11.1 \%$ to $4.4 \%$ from no-load to a full load for a $200 \mathrm{kV} / 20 \mathrm{~mA}$ HUST-ICT prototype. Moreover, the load regulation is greatly reduced from $14.3 \%$ to $9.6 \%$. The method improves the stability and reliability of the ICT high voltage power supply and greatly reduces the design time.
\end{abstract}

Keywords: insulation core transformer; non-uniformity of disk output voltage; load regulation; voltage compensation; dummy primary winding; PSO algorithm

\section{Introduction}

Low-energy electron accelerators have been widely adopted in the fields of material modification, environmental protection, treatment, coating curing, etc. [1-3]. Compared with other types of electron accelerators for industrial irradiation applications, insulated core transformers (ICTs) have the outstanding advantage of high energy conversion efficiency. The performance of an electron accelerator largely depends on the high-voltage power supply.

Recently, ICT high-voltage power supply involved in attention due to high-power density. In 2009, KSI Corp. developed a novel ICT of 750 kV /100 mA [4]. In 2011, a planar ICT was designed by the Chinese Academy of Sciences, and the capacitor compensation technique is adopted [5]. Since 2012, compensation methods [6,7] and equivalent circuit models [8-10] have been developed at Huazhong University of Science and Technology.

The plane schematic diagram of a three-phase ICT is presented in Figure 1. It contains three core columns, which consist of a primary core wrapped with a primary winding and multi-secondary cores wrapped with multi-secondary windings. Insulation sheets are inserted between the cores [11]. Each core is electrically connected to the corresponding winding to achieve equipotential, and each of the three secondary windings in the same disk is connected to a DC voltage doubler. The three doubler units in the same disk are connected in series; this output DC voltage is called the disk output voltage. Each disk 
is surrounded by a grading ring, which is intended to distribute the electric field evenly. Finally, all disks are connected in series to obtain the high output voltage of the ICT highvoltage power supply [7]. The ICT and the high-voltage electrode on top of it are placed into a tank filled with approximately $0.6 \mathrm{Mpa}$ sulfur hexafluoride gas.

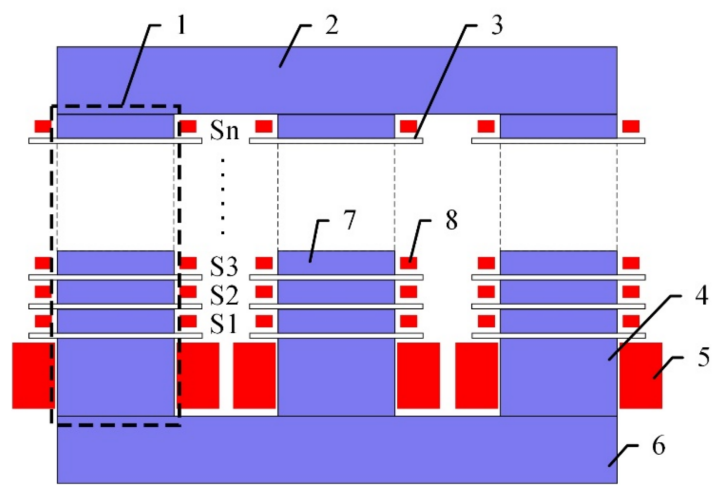

Figure 1. Plane schematic diagram of a three-phase ICT. 1-magnetic core limb; 2-top yoke; 3-insulation sheet; 4-primary core; 5-primary winding; 6-bottom yoke; 7-secondary core; 8 - secondary winding. Sn represents the $n$-th disk.

The insulation sheets are usually made of Teflon, mica, etc., for which the magnetic permeability is much smaller than that of electrical steel. Significant magnetic flux leakage is produced by the insulation sheets of ICTs $[9,12]$. The leakage flux gradually increases from the bottom to the top disk $[6,13]$. The output voltage of disks is proportional to the working frequency, the flux amplitude, and the number of secondary winding turns. The different output voltages of the disks cause electric potential differences among the disks. On the one hand, the induced voltages of the secondary windings on different disks are different, which results in higher design and manufacturing costs. On the other hand, a permanently damaging electric breakdown tends to occur on insulating sheets between adjacent disks that have a large electric potential difference.

Increasing the number of secondary winding turns is commonly used to ensure that the disks' output voltage is as consistent as possible. To facilitate the description of the consistency of the disks' output voltage, the concept of maximum non-uniformity is introduced. The maximum non-uniformity of the disks' output voltage can be used to describe the distribution of the output voltage of all disks, indicating the possibility of high voltage breakdown. It can be defined as:

$$
\begin{gathered}
\sigma_{0}=\frac{\max \left(V_{s j_{-} N L}\right)-\min \left(V_{s j_{-} N L}\right)}{\max \left(V_{s j_{-} N L}\right)} \times 100 \% \\
\sigma_{1}=\frac{\max \left(V_{s j_{-} F L}\right)-\min \left(V_{s j_{-} F L}\right)}{\max \left(V_{s j_{-} F L}\right)} \times 100 \%
\end{gathered}
$$

where $\sigma_{0}$ and $\sigma_{1}$ represent the maximum non-uniformity of disk output voltage under no-load conditions and full load conditions, respectively; $V_{S j}$ represents the output voltage of the $j$-th disk $S_{j}, j \leq n$; and $n$ represents the number of disks.

Often, the upper secondary windings require an additional number of turns, which increases the output impedance. Eventually, this leads to a greater load regulation of the upper disks than the lower disks. Load regulation describes the change in the output voltage from no-load to a full load, which can be expressed by Formula (2):

$$
L R=\frac{V_{\text {no-load }}-V_{\text {fullload }}}{V_{\text {fulload }}} \times 100 \%
$$


where $L R$ represents the load regulation, and $V_{\text {no-load }}$ and $V_{\text {fullload }}$ represent the output high voltage under no-load conditions and full load conditions, respectively.

The differing load regulation of disks creates more challenges in selecting an appropriate number of secondary winding turns. We developed a $200 \mathrm{kV} / 20 \mathrm{~mA}$ HUST-ICT prototype, and Figure 2 shows the equipment during installation at Huazhong University of Science and Technology. The conversion efficiency of the HUST-ICT was up to $86 \%$. The number of secondary winding turns $\left(\mathrm{N}_{\mathrm{S} 1}, \mathrm{~N}_{\mathrm{S} 2}, \ldots, \mathrm{N}_{\mathrm{S6}}\right)$ was $2736,3080,3400,3671,3863$, and 3974.

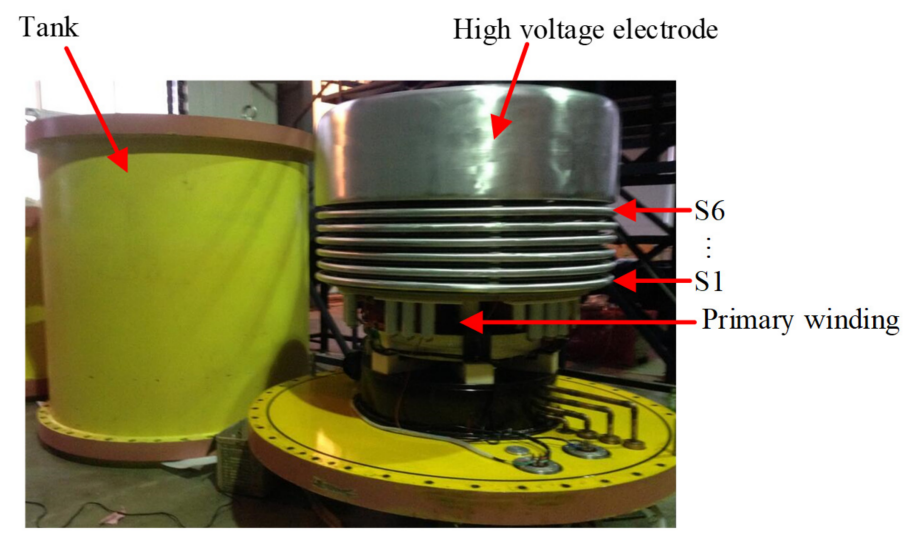

Figure 2. A 200 kV / 20 mA prototype HUST-ICT during installation.

The output voltage of the disk was tested in an atmospheric insulated environment with a high voltage of $20 \mathrm{kV}$ under no- load. Figure 3 shows the output voltage of each disk, which was approximately $3.5 \mathrm{kV}$. The maximum error between the simulation results obtained via the finite-element method (FEM) and the experimental data was less than $5.5 \%$. Because measurement of the output voltage of the disks was not possible under $200 \mathrm{kV}$ operating conditions, the 3D FEM model and a circuit model of the HUST-ICT were built and examined with Ansys software and the MATLAB/Simulink environment, respectively. The distribution of the magnetic flux density in the 3D FEM model is shown in Figure 4. Figure 5 shows the results of the two simulation methods when the HUSTICT was working at $200 \mathrm{kV}$ with no- load and a full load. These results also match the experimental data when the accelerator was working at $200 \mathrm{kV} / 20 \mathrm{~mA}$. The maximum error between the simulation results obtained via the FEM and the simulated circuit was less than $2.5 \%$. Therefore, the FEM simulation model was considered to be reliable.

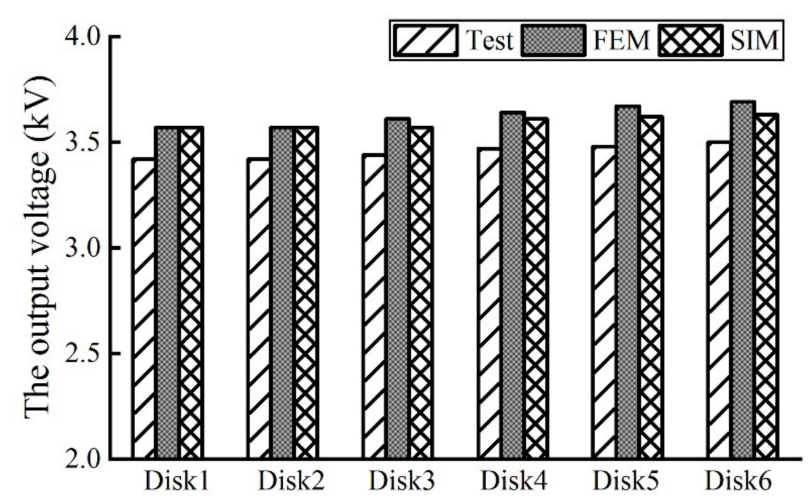

Figure 3. The output voltage distribution of disks under no-load from the experimental test, FEM, and Simulink circuit simulations. 


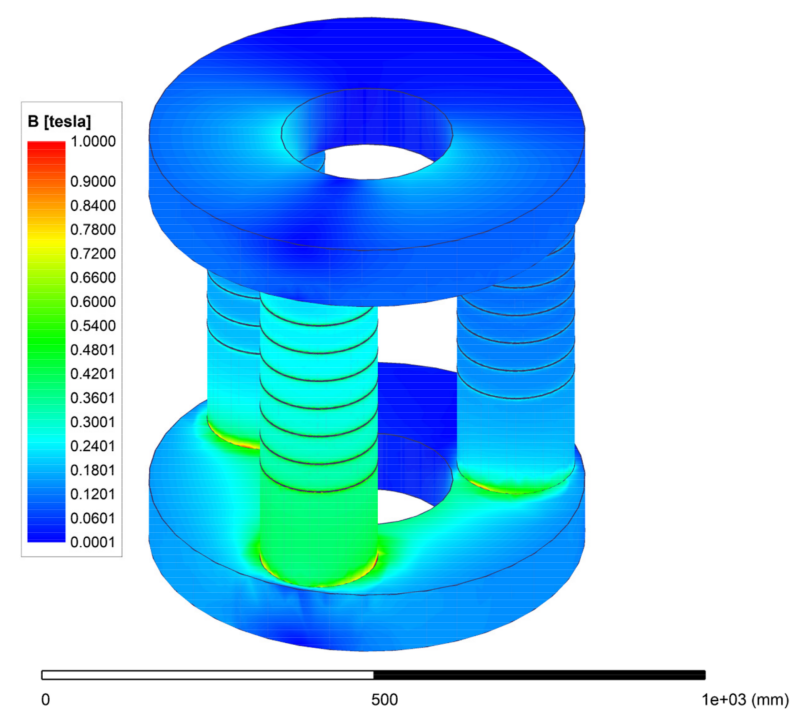

Figure 4. Distribution of the magnetic flux density in the 3D FEM model of the HUST-ICT.

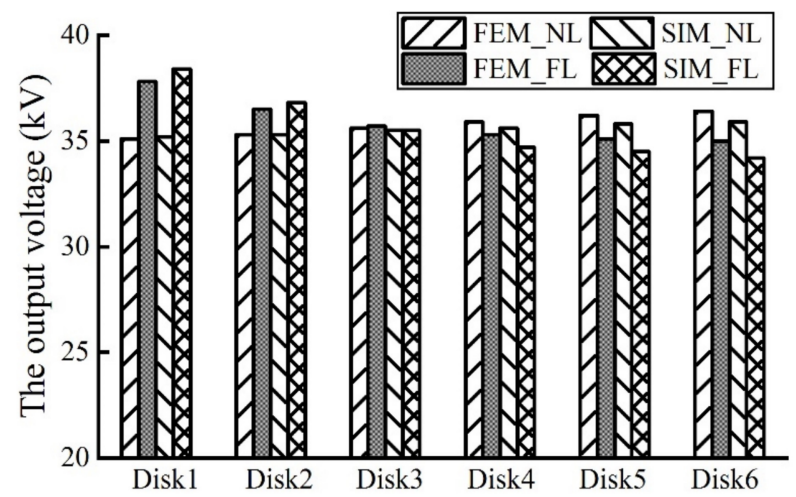

Figure 5. The output voltage distribution of disks at $200 \mathrm{kV}$ under no-load and a full load obtained via FEM and Simulink circuit simulations. NL, no-load; FL, full load.

$\sigma_{0}$ was $3.5 \%$ and $\sigma_{1}$ was $11.1 \%$ based on the FEM simulation model. Although the non-uniformity of the disk output voltage was small under no-load, it was larger under a full load. Usually, both $\sigma_{0}$ and $\sigma_{1}$ are expected to be less than $10 \%$ to ensure reliable operation in industrial production systems. The $L R$ of the HUST-ICT was $14.3 \%$. The smaller the load regulation, the better the performance of the ICT high-voltage power supply. Notably, $\sigma$ and $L R$ did not meet expectations. Several electric breakdowns occurred on the insulation sheets.

In addition, a significant amount of time can be spent on the design of the number of secondary turns with manual iterative optimization, which mainly relies on the designer's experience. The design of an ICT contains many parameters, which interact with the transients. As a result, the manual optimization process is complex, and the result is frequently not an optimal solution for this problem.

Methods of optimizing and improving the prototype are currently being studied. On the one hand, adding a dummy primary winding is an interesting method [7]. Dummy primary winding produces a greater excitation effect on the upper secondary windings than on the lower ones. It creates a complementary effect with the primary winding and helps to improve the uniformity of the disks' output voltage. On the other hand, artificial intelligence algorithms can be used to optimize the design parameters of an ICT. The PSO algorithm is a metaheuristic algorithm, which was developed by Kennedy and Eberhart in 1995 [14]. In comparison with other algorithms (GA, ACO, ABC, GSO, SA, etc.), the major advantages of PSO include fewer control parameters, high efficiency, fast convergence, 
and little dependence on the initial value [15]. It has been successfully applied to both continuous and discrete optimization problems. More recently, the PSO algorithm has solved many complex scientific research and engineering application problems [16-19].

In the light of the discussion above, the design parameters of an insulated core transformer with a dummy primary winding (DICT) were optimized based on the PSO algorithm in this research. The remaining parts of this study are organized as follows.

The structure of the DICT is introduced and the parameters are calculated analytically in Section 2. The optimization methods based on PSO are described in Section 3. The method is presented as an example of a $200 \mathrm{kV} / 20 \mathrm{~mA}$ DICT in Section 4 . The results are analyzed and discussed in Section 5. Section 6 concludes this paper.

\section{Design of DICT}

\subsection{The DICT Structure}

In contrast to conventional structures, one dummy primary winding and one dummy primary core are added to the top of each phase limb of the ICT. The structural dimensions of the dummy primary windings and cores are the same as those of the primary windings and cores. The dimensional parameters of the ICT are listed in Table 1. The structure diagram of a three-phase DICT with six disks is shown in Figure 6.

Table 1. The dimensional parameters of DICT structure.

\begin{tabular}{ccc}
\hline Components & Height $(\mathbf{m m})$ & Radius $(\mathbf{m m})$ \\
\hline (Dummy) primary cores & 170 & 89 \\
\hline Secondary cores & 47.6 & 89 \\
\hline (Dummy) primary windings & 150 & 94 (inner) $/ 139$ (outer) \\
\hline Secondary windings & 25 & 96 (inner) $/ 131$ (outer) \\
\hline Yokes & 100 & 130 (inner) $/ 330$ (outer) \\
\hline Insulation sheets & 2 & 100 \\
\hline
\end{tabular}

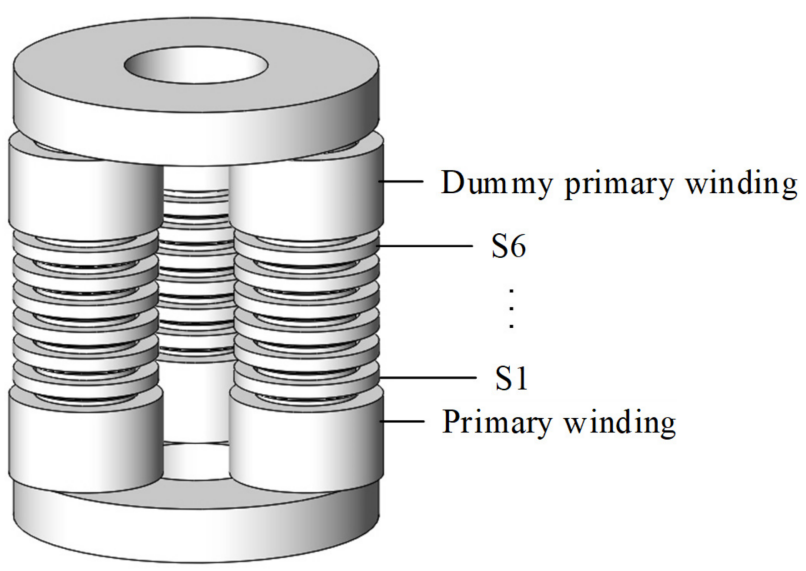

Figure 6. Structure diagram of the three-phase DICT with six disks.

The alternating magnetic flux produced by the primary winding excitation generates an induced voltage in the dummy primary winding. A suitable capacitor (calculated in the next subsection) is connected in parallel to each dummy primary winding. The current phase of the dummy primary winding is adjusted so that it is consistent with the current phase of the primary winding. This seems to increase the excitation to compensate for the magnetic flux of the secondary windings, especially the upper secondary windings. Therefore, this capacitor can be called a compensation capacitor. 


\subsection{Calculation of the Parameters}

An ICT is a multi-winding transformer with a special structure. It is very difficult to calculate the exact value of mutual inductance using analytical expressions because the fringing flux effect around all the insulation sheets makes the calculation of the flux path complicated [20]. Numerical analysis via FEM allows for a high-precision mutual inductance matrix.

Due to the completely symmetrical structure, the magnetic circuits of each phase are equal. The equations used to calculate the number of secondary winding turns and compensation capacitance were derived and are described for a single-phase expression in the following paragraphs.

The voltage balance equations of the ideal transformer model and Ohm's Law under no- load conditions are shown below:

$$
\begin{gathered}
\dot{U}_{p}=j \omega L_{p} \dot{I}_{p}+j \omega M_{p p^{\prime}} \dot{I}_{p^{\prime}}+R_{p} \dot{I}_{p} \\
\dot{U}_{p^{\prime}}=j \omega L_{p^{\prime}} \dot{I}_{p^{\prime}}+j \omega M_{p p^{\prime}} \dot{I}_{p}+R_{p^{\prime}} \dot{I}_{p^{\prime}} \\
\dot{U}_{p^{\prime}}=-\frac{1}{j \omega C_{c o m}} \dot{I}_{p^{\prime}}
\end{gathered}
$$

where $p$ and $p^{\prime}$ represent the primary winding and the dummy primary winding, $U_{p}$ and $U_{p^{\prime}}$ represent the voltage of the primary winding and the dummy primary winding, $I_{p}$ and $I_{p}$ represent the current of the primary winding and the dummy primary winding, $R_{p}$ and $R_{p^{\prime}}$ represent the resistance of the primary winding and the dummy primary winding, $L_{p}$ and $L_{p^{\prime}}$ are the self-inductance of the primary winding and the dummy primary winding, $M_{p p^{\prime}}$ is their mutual inductance, $\omega$ is the angular frequency of the input voltage, and $C_{c o m}$ is the capacitance connected to each dummy primary winding. The resistance of the windings is much smaller than the inductive reactance and can be neglected for simplified calculations. It is necessary to generate the same excitation effect for the dummy primary windings as the primary windings. Hence, the flux of the primary winding is equal to that of the dummy primary winding, corresponding to their induced voltages. Ultimately, the compensation capacitance can be calculated by Equation (6):

$$
C_{c o m}=\frac{L_{p}-M}{\omega^{2}\left(L_{p} L_{p^{\prime}}-M^{2}\right)}
$$

This is related to the mutual inductance parameters and the angular frequency of the input voltage. Once the physical model has been established, the mutual inductance matrix can be obtained by FEM simulation or a formula based on experience, which can be used to calculate a preliminary value of compensation capacitance. This is optimized in Section 3.

The excitation generated by the primary windings and the dummy primary windings is cross-linked with all other windings, which satisfies the superposition theorem [21].

$$
\begin{gathered}
\dot{U}=j \omega\left(L_{p}+M_{p p^{\prime}}\right) \dot{I} p+j \omega\left(L_{p^{\prime}}+M_{p p^{\prime}}\right) \dot{I}_{p^{\prime}} \\
N_{S i}=\frac{U_{S i}}{U_{p}} \frac{L_{p}{ }^{(1)}+L_{p^{\prime}}{ }^{(1)}}{M_{p S i}{ }^{(1)}+M_{p^{\prime} S i}{ }^{(1)}} N_{p} k_{1}
\end{gathered}
$$

where $N_{p}$ and $N_{S} i$ are the number of primary and secondary winding turns, respectively; $L_{p}{ }^{(1)}, L_{p^{\prime}}{ }^{(1)}, M_{p S i}{ }^{(1)}$ and $M_{p^{\prime} S i}{ }^{(1)}$ are the single-turn self- and mutual- inductance of the windings; $U_{p}$ is the input RMS voltage of the primary winding; $U_{S i}$ is the output RMS voltage of the secondary windings; and $k_{1}$ is a compensation coefficient. 


\section{Optimization Method for the Design Parameters of the DICT Based on PSO}

The parameters of the DICT to be optimized included the number of secondary winding turns $\left(\mathrm{N}_{\mathrm{S} 1}, \mathrm{~N}_{\mathrm{S} 2}, \ldots, \mathrm{N}_{\mathrm{Sn}}\right)$ and the compensation capacitance $\left(C_{\text {com }}\right)$. Obviously, this is a multi-parameter optimization problem in a typical engineering application.

The PSO algorithm mimics the foraging behavior of certain birds or other animals, which find food through their knowledge and learning from the experiences of others, there are no leaders among them. The PSO is similar to the genetic algorithm (GA) in that the system is initialized by a population of randomized solutions. Compared with the GA, each potential solution in the PSO has a random velocity, and these potential solutions are particles flying in a multi-dimensional space. They adjust their flight speed dynamically according to the individual cognitive ability and the social cognition ability (from the experience of their peers), which form positive feedback for group optimization. Each particle records its coordinates (position) associated with the best solution (the maximum or minimum value of the target function) that it has achieved so far in the search space. This value is called pbest. Meanwhile, the best solution of all particles is also recorded, this value is called gbest [22]. Next, pbest and gbest are updated through each iteration step. Specifically, at the $k$-th iteration, the speed and position of the $i$-th particle are updated through dimension $d$ according to the following Equations [15]:

$$
\begin{gathered}
v_{i, d}^{k+1}=\omega v_{i, d}^{k}+c_{1} r_{1}\left(\text { pbest } i_{i, d}^{k}-x_{i, d}^{k}\right)+c_{2} r_{2}\left(\text { gbest } t_{d}^{k}-x_{i, d}^{k}\right) \\
x_{i, d}^{k+1}=x_{i, d}^{k}+v_{i, d}^{k}
\end{gathered}
$$

where $c_{1}$ is the learning coefficient for individual ability and $c_{2}$ is the learning coefficient for social ability. Usually, $c_{1}$ and $c_{2}$ are taken as 2. Moreover, $r_{1}$ and $r_{2}$ are uniform random numbers between 0 and $1, d$ represents the dimension, and $w$ is the inertia weight, which plays an important role in balancing the global search and the local search, since it directly affects the convergence of the objective function. It helps to reduce interactions by using a decreasing inertia weight.

The PSO algorithm is ideal for solving multi-parameter optimization problems by constructing an objective function and converting the multiple parameters to be solved into a multi-dimensional solution space. In this study, the objective function involved $\sigma_{0}$, $\sigma_{1}$, and $L R$.

The position of the particle is a variable vector $X=\left[x_{1}, x_{2}, \ldots, x_{m}\right]$ that indicates the solution of the problem to be optimized for a swarm with $\mathrm{m}$ particles. The merit of the position for each particle depends on the objective function.

Combined with the design processes of the DICT, the PSO-based method is summarized in the following steps:

1. Select the material of the insulating sheets, the rectifier elements, and the working magnetic flux density based on the minimum power loss and the size of the structure of the DICT, and calculate the rough value of $C_{c o m}$ and $\mathrm{N}_{\mathrm{S} 1}, \mathrm{~N}_{\mathrm{S} 2}, \ldots, \mathrm{N}_{\mathrm{Sn}}$ according to Equations (6) and (8);

2. Calculate the mutual inductance matrix with the FEM magnetostatic model of the DICT;

3. Generate an initial swarm with positions $\left(\mathrm{x}_{\mathrm{i}}\right)$ and velocities $\left(\mathrm{v}_{\mathrm{i}}\right)$. Take a range of values for each particle based on the previous calculations of $\mathrm{N}_{\mathrm{S} 1}, \mathrm{~N}_{\mathrm{S} 2}, \ldots, \mathrm{N}_{\mathrm{Sn}}$, and $C_{\text {com }}$;

4. Establish the objective function and obtain the personal best value pbest and the global best value gbest so far. $\mathrm{V}_{\mathrm{S} 1 \_\mathrm{NL}}, \mathrm{V}_{\mathrm{S} 2 \_\mathrm{NL}}, \ldots, \mathrm{V}_{\mathrm{Sn} \_\mathrm{NL}}$ are calculated by analytical formulae. Meanwhile, $\mathrm{V}_{\mathrm{S} 1 \_} \mathrm{FL}_{1}, \mathrm{~V}_{\mathrm{S} 2 \_\mathrm{FL}}, \ldots, \mathrm{V}_{\mathrm{Sn} \_ \text {FL }}$ are obtained by the MATLAB codes and the Simulink circuit under full load conditions. Thus, $\sigma_{0}, \sigma_{1}$ and $L R$ can be calculated by Formulas (1) and (2);

5. Update the personal best value pbest and the global best value gbest, and update the position and velocity of each particle via Equations (9) and (10) to obtain a new set of design parameters;

6. Assess the objective function and find the best fitness value so far; 
7. Update the swarm, and repeat Steps 4, 5, and 6;

8. Repeat Steps 4, 5, 6, and 7 until the end condition is met;

9. Output the optimized parameters of the DICT $\left(\mathrm{N}_{\mathrm{S} 1}, \mathrm{~N}_{\mathrm{S} 2}, \ldots, \mathrm{N}_{\mathrm{Sn}}, C_{\text {com }}\right)$ and the output voltage of disks $\left(\mathrm{V}_{\mathrm{S} 1 \_N L}, \mathrm{~V}_{\mathrm{S} 2 \_N L}, \ldots, \mathrm{V}_{\mathrm{Sn}_{-} \mathrm{NL}}, \mathrm{V}_{\mathrm{S} 1_{-} \mathrm{FL}}, \mathrm{V}_{\mathrm{S} 2 \_\mathrm{FL}}, \ldots, \mathrm{V}_{\mathrm{Sn} \_\mathrm{FL}}\right)$, and calculate $\sigma_{0}, \sigma_{1}$, and $L R$;

10. Import the optimized parameters into the FEM couple-circuit transient model of the DICT to verify the output voltage of the disks.

A flowchart of the design parameters of a DICT based on PSO is shown in Figure 7.

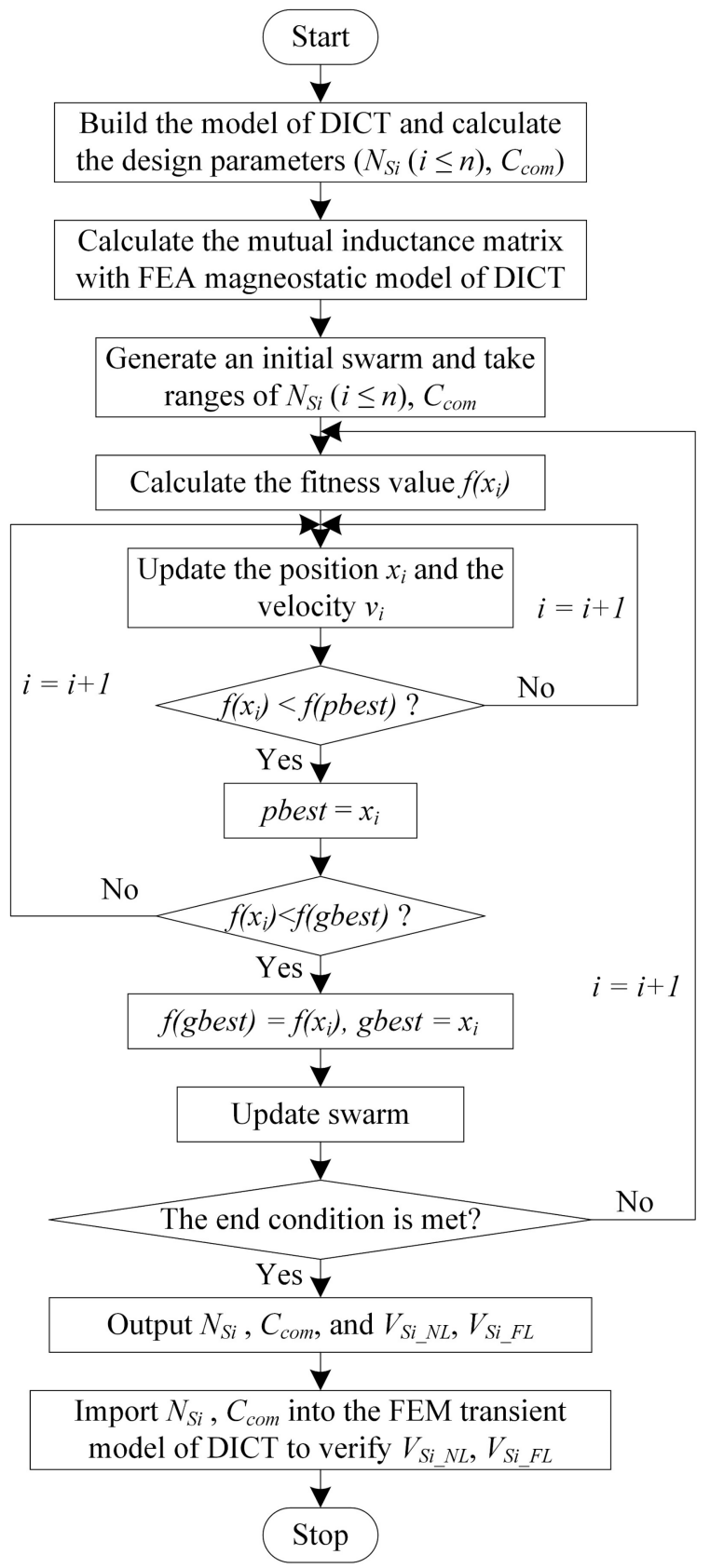

Figure 7. Flowchart of the design parameters of a DICT based on PSO.

\section{An Example of a $200 \mathrm{kV} / 20 \mathrm{~mA}$ DICT}

Based on the experience of the prototype, the fill factor of the core was about $95 \%$, and the core material was Nippon steel of 27zh95, the BH curve for which is shown in Figure 8. The material of windings is copper and the windings are modelled using uniform multiturn coils. At the same time, sufficient space needs to be considered for coil interleaving 
and interlayer insulation. The doubling rectifier circuit is the same as in [6], expect that the capacitor is set to $0.2 \mu \mathrm{F}$. The smaller capacitor helps to reduce stored energy and increase the reliability of the ICT. The mutual inductance matrix can be obtained with the FEM magnetostatic model. The design parameters were optimized by the method described in Section 3.

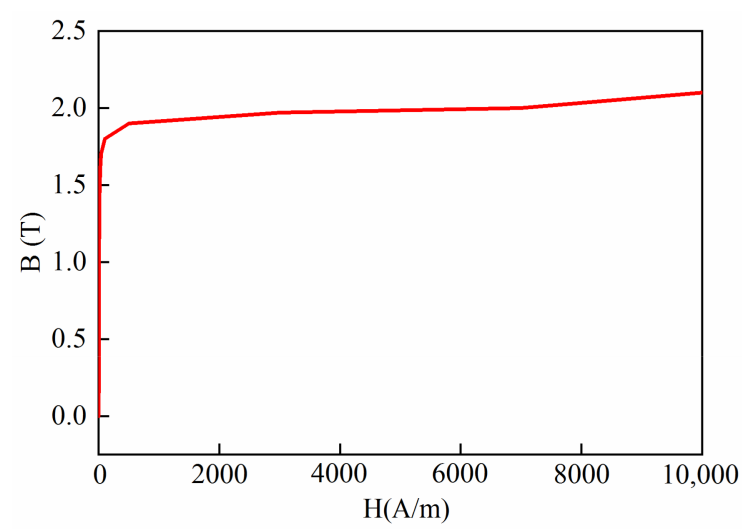

Figure 8. The BH curve of 27zh95 steel.

The working magnetic flux density was about $0.5 \mathrm{~T}$, which is much lower than the saturation value, except for the corners. As a consequence, it can be described by a linear transformer model [8]. The compensation capacitance $C_{\text {com }}$ was $213 \mu \mathrm{F}$, and the number of secondary winding turns $\left(\mathrm{N}_{\mathrm{S} 1}, \mathrm{~N}_{\mathrm{S} 2}, \ldots, \mathrm{N}_{\mathrm{S} 6}\right)$ was 1997, 2097, 2146, 2146, 2097, and 1997, respectively, according to Equations (6) and (8). For simplicity, the dummy primary winding was assumed to be the same size as the primary windings. $\mathrm{N}_{\mathrm{p}^{\prime}}$ was the same as $\mathrm{N}_{\mathrm{p}}$ : they were both 92 turns, and $\mathrm{N}_{\mathrm{S} 1}$ was 2000 turns, based on the preliminary design.

\subsection{Initialization}

Depending on the design, the number of secondary winding turns is determined to be in the range of 1500-4000, and the compensation capacitance is taken in the range of 100-300 $\mu \mathrm{F}$. Any phase of the ICT with a symmetric structure contains sufficient mutual inductance information. The problem has six dimensions with solution variables $\left(\mathrm{N}_{\mathrm{S} 2}\right.$, $\left.\mathrm{N}_{\mathrm{S} 3}, \ldots, \mathrm{N}_{\mathrm{S} 6}, \mathrm{C}_{\mathrm{com}}\right)$. The dynamic inertia weight $\mathrm{w}$ is in the range of $0.4-0.95$, and a linear reduction was carried out by Equation (11) during the training. The population size was set to 100, and the maximum number of iterations was set to 60 .

$$
w=\frac{\operatorname{Max} I t-I t}{\operatorname{Max} I t} \times\left(w_{s}-w_{e}\right)+w_{e}
$$

where $w_{s}$ and $w_{e}$ represent the initial value and the end value of inertia weight, respectively. MaxIt represents the maximum number of iterations; and It represents the current number of iterations.

\subsection{The Objective Function}

The non-uniformity of the disks' output voltage and load regulation are the main factors to be considered; hence, the objective function consists of these two factors. The objective function is established with the non-uniformity of the disks' output voltage and load regulation, which can be set as in Equation (12):

$$
\text { fitness }=\omega_{1} \times \max \left(\sigma_{0}, \sigma_{1}\right)+\omega_{2} \times L R
$$

where $\omega_{1}$ and $\omega_{2}$ represent the weights of non-uniformity and load regulation, respectively. Because the non-uniformity is a more important indicator affecting an ICT's performance, the weight factor $\omega_{1}$ was set to 1 , and $\omega_{2}$ was set to 0.3 , based on the experience of the designer. 


\section{Results}

The convergence curve of the PSO algorithm is shown in Figure 9, and the optimized design parameters are listed in Table 2 . The results of the FEM model are in good agreement with the results of MATLAB/Simulink.

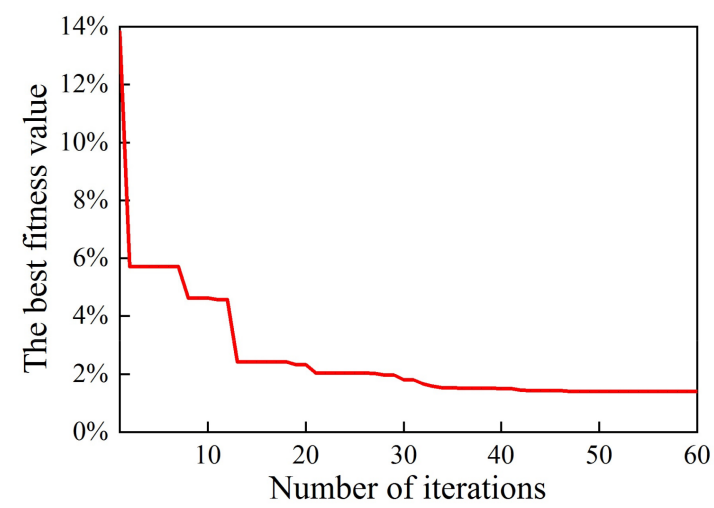

Figure 9. The best fitness value per generation calculated by PSO for the DICT.

Table 2. The optimized design parameters of the DICT.

\begin{tabular}{ccccccc}
\hline Disk No. & S1 & S2 & S3 & S4 & S5 & S6 \\
\hline Number of turns & 2000 & 2122 & 2190 & 2188 & 2124 & 2024 \\
\hline Capacitance $\left(C_{\text {com }} / \mu \mathrm{F}\right)$ & \multicolumn{7}{c}{215} \\
\hline
\end{tabular}

The distributions of the disks' output voltage after all the tests and optimizations with different types under no- load and a full load by FEM simulation are shown in Figure 10. The distribution of the magnetic flux density in the 3D FEM model of the DICT is shown in Figure 11. A comparison of the distribution of the magnetic flux density in the central axis of the A-phase core column between the HUST-ICT and the DICT is shown in Figure 12. Compared with Figure 4, the uniformity of the magnetic flux density distribution of ICT has been significantly improved.

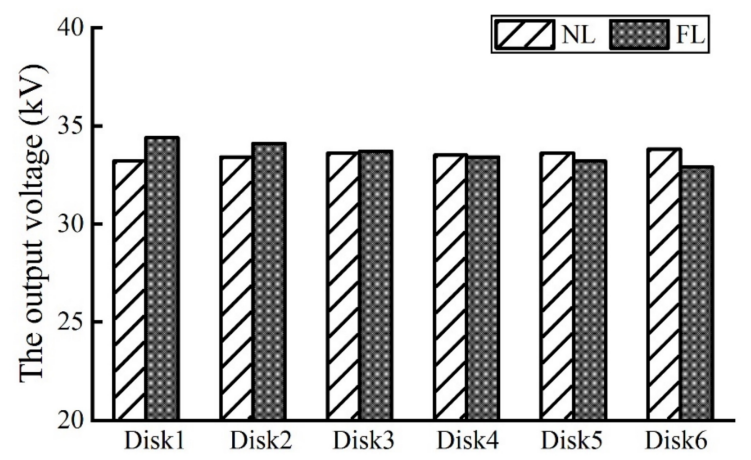

Figure 10. The DICT output voltage distribution of disks under no-load and a full load by FEM simulation after PSO. NL, no- load; FL, full load. 


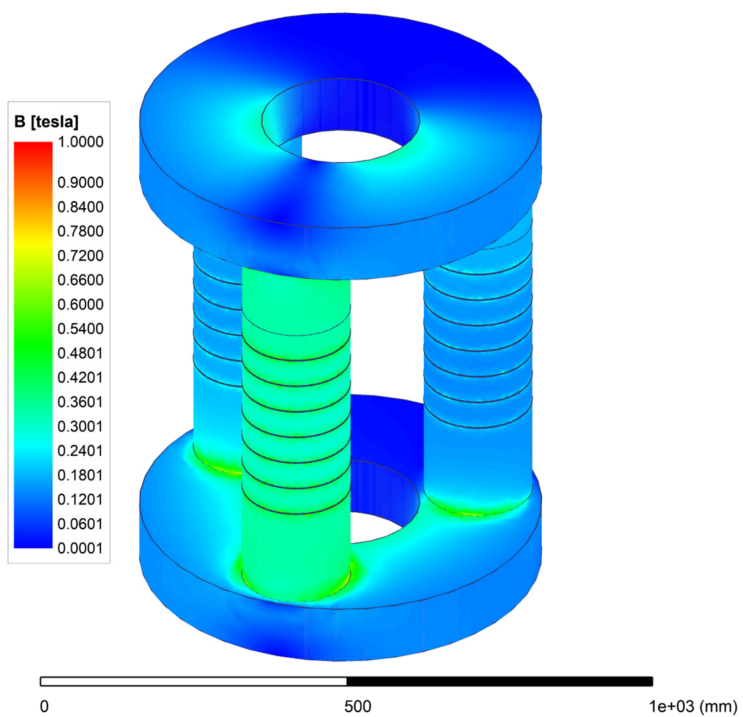

Figure 11. Distribution of the magnetic flux density in the 3D FEM model of the DICT.

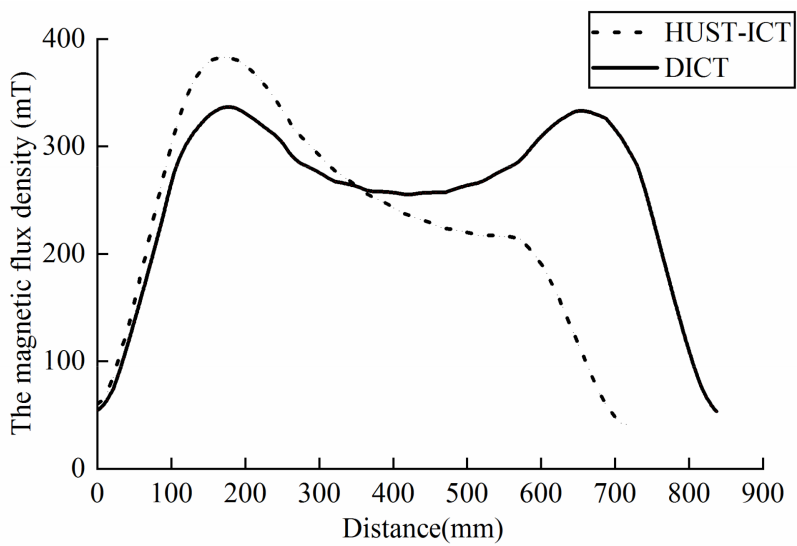

Figure 12. A comparison of the distribution of the magnetic flux density in the central axis of the A-phase core column between the HUST-ICT and the DICT.

The results based on PSO show that both $\sigma_{0}$ and $\sigma_{1}$ were less than $1.5 \%$. However, $\sigma$ tended to be larger in the FEM model, especially $\sigma_{1}$. The difference between the two simulation methods can be attributed to a minor current phase shift in the dummy primary windings. Compared with the circuit simulation model, the FEM model is more reliable. Therefore, the final results based on the FEM simulation are presented in Table 3. In comparison with the HUST-ICT under $200 \mathrm{kV} / 20 \mathrm{~mA}$, the DICT has obvious advantages over ICT. The non-uniformity of the disks' output voltage decreases, from 3.5\% to $1.9 \%$ under no-load and from $11.1 \%$ to $4.4 \%$ under a full load. Moreover, the load regulation is greatly reduced to $9.6 \%$.

Table 3. Comparison of optimization results with $200 \mathrm{kV} / 20 \mathrm{~mA}$.

\begin{tabular}{cccc}
\hline \multirow{2}{*}{ Type } & \multicolumn{2}{c}{ Non-Uniformity } & \multirow{2}{*}{ Load Regulation } \\
\cline { 2 - 3 } & No-Load & Full Load & \\
\hline HUST-ICT & $3.5 \%$ & $11.1 \%$ & $14.3 \%$ \\
\hline DICT by PSO & $1.9 \%$ & $4.4 \%$ & $9.6 \%$ \\
\hline
\end{tabular}

In addition, the PSO method takes only a few hours, whereas the manual optimization method takes several days or even weeks. In summary, the PSO method proved to be far superior to the manual optimization method. 
The number of secondary winding turns was greatly reduced, especially for secondary windings in the upper disks. Moreover, the number of winding turns had a roughly symmetrical distribution, which reduced the number of winding specifications. As a result, this suggested higher feasibility for the project's implementation.

\section{Conclusions}

In this paper, the accuracy of the FEM model was verified by comparing test data of the HUST-ICT prototype with the simulation results, and consistent results were also verified in MATLAB/Simulink. The PSO algorithm was proposed for optimizing the design parameters of ICT. The structure of the DICT made the electric field evenly distributed, ensured the uniformity of the disks' output voltage, and greatly reduced the load regulation.

The PSO-based optimization method turned out to be highly effective for achieving better disk output voltage uniformity and load regulation for the DICT. In summary, it significantly saves the design time needed to improve an ICT's performance. The optimized design codes developed here can be used for all ICT-type high-voltage power supply systems. Future work is planned to develop a new prototype based on this method.

Author Contributions: Conceptualization, C.J. and J.Y.; methodology, C.J.; software, C.J.; validation, C.J. and J.Y.; investigation, C.J. and J.Y.; resources, J.Y.; data curation, C.J.; writing-original draft preparation, C.J.; writing-review and editing, J.Y.; project administration, J.Y. and M.F.; funding acquisition, M.F. All authors have read and agreed to the published version of the manuscript.

Funding: This research was funded by the Technological Innovation Program of Hubei Province, China (grant number 2017AEA107).

Data Availability Statement: The data that support the findings of this study are available from the corresponding author upon reasonable request.

Acknowledgments: We acknowledge the financial support provided by the Department of Science and Technology of Hubei Province.

Conflicts of Interest: The authors declare no conflict of interest.

\section{References}

1. Knyazeva, A.G.; Kushch, V.I.; Remnev, G.E.; Ezhov, V.V.; Smolyanskiy, E.A. Tin coating effect on the elastoplastic behaviour of ti film for electron beam exit window. Vacuum 2017, 143, 356-362. [CrossRef]

2. Chmielewski, A.G.; Al-Sheikhly, M.; Berejka, A.J.; Cleland, M.R.; Antoniak, M. Recent developments in the application of electron accelerators for polymer processing. Radiat. Phys. Chem. 2014, 94, 147-150. [CrossRef]

3. Parejo Calvo, W.A.; Duarte, C.L.; Machado, L.D.B.; Manzoli, J.E.; Geraldo, A.B.C.; Kodama, Y.; Silva, L.G.A.; Pino, E.S.; Somessari, E.S.R.; Silveira, C.G.; et al. Electron beam accelerators-Trends in radiation processing technology for industrial and environmental applications in latin america and the caribbean. Radiat. Phys. Chem. 2012, 81, 1276-1281. [CrossRef]

4. Uhmeyer, U. Ksi's cross insulated core transformer technology. AIP Conf. Proc. 2009, 1149, 1099-1103.

5. Cheng, K.; Yonghao, L.; Deming, L.I. Analysis of output voltage on a planar insulating core transformer. Nuclear Sci. Tech. 2012, 22, 15-18.

6. Yang, L.; Yang, J.; Liu, K.F.; Qin, B.; Chen, D.Z. A combined compensation method for the output voltage of an insulated core transformer power supply. Rev. Sci. Instrum. 2014, 85, 063302. [CrossRef] [PubMed]

7. Jiang, C.; Yang, J.; Tang, K.; Liu, T.; Xi, C.; Ye, J.; Yu, T.; Fan, M. A hybrid compensation method for ict high voltage power supply. IEEE Trans. Appl. Supercond. 2020, 30, 0600105. [CrossRef]

8. Cao, L.; Yang, J. Linear circuit model of the three-phase insulated core transformer power supply. IEEE Trans. Nucl. Sci. 2016, 63, 288-296. [CrossRef]

9. Hu, J.; Cao, L.; Yang, B.; Yang, J. Leakage inductance calculation of the insulated core transformer. J. Huazhong Univ. Sci. Technol. 2016, 44, 47-50.

10. Yang, B.; Cao, L.; Yang, J.; Yan, S.-C.; Tao, Y.-B. Equivalent circuit model for the insulated core transformer. Nucl. Sci. Tech. 2016, 27, 68. [CrossRef]

11. Graaff, R.V.D.J. High Voltage Electromagnetic Apparatus Having an Insulating Magnetic Core. U.S. Patent 3187208, 6 January 1965.

12. Luo, M.; Dujic, D.; Allmeling, J. Leakage flux modeling of medium-voltage phase-shift transformers for system-level simulations. IEEE Trans. Power Electron. 2019, 34, 2635-2654. [CrossRef] 
13. Frost, R.E.P.; Pilgrim, J.A.; Lewin, P.L.; Spong, M. An investigation into the next generation of high density, ultra high voltage, power supplies. In Proceedings of the 2018 IEEE International Power Modulator and High Voltage Conference, Jackson, WY, USA, 3-7 June 2018; pp. 156-161.

14. Eberhart, R.C.; Kennedy, J. A new optimizer using particle swarm theory. In Proceedings of the Sixth International Symposium on Micro Machine and Human Science, Nagoya, Japan, 4-6 October 1995.

15. Sibalija, T.V. Particle swarm optimisation in designing parameters of manufacturing processes: A review (2008-2018). Appl. Soft Comput. 84 2019, 84, 105743. [CrossRef]

16. Zhou, P.; Ma, X.; Zhang, S.; Liu, Z.; Meng, Z.; Xiang, Z.; Wang, X.; Sun, T.; Lin, X.; Li, Y. Application of particle swarm optimization in the design of a mono-capillary x-ray lens. Nucl. Instrum. Methods Phys. Res. 2020, 953, 163077. [CrossRef]

17. Liu, Z.H.; Wei, H.L.; Li, X.H.; Liu, K.; Zhong, Q.C. Global identification of electrical and mechanical parameters in pmsm drive based on dynamic self-learning pso. IEEE Trans. Power Electron. 2018, 33, 10858-10871. [CrossRef]

18. Godio, A.; Santilano, A. On the optimization of electromagnetic geophysical data: Application of the pso algorithm. J. Appl. Geophys. 2018, 148, 163-174. [CrossRef]

19. Yan, R.Q.; Wang, T.; Jiang, X.; Zhong, Q.; Yue, X.Z. Design of high-performance plasmonic nanosensors by particle swarm optimization algorithm combined with machine learning. Nanotechnology 2020, 31, 375202. [CrossRef] [PubMed]

20. Akbari, M.; Rezaei-Zare, A.; Cheema, M.A.M.; Kalicki, T. Air gap inductance calculation for transformer transient model. IEEE Trans. Power Deliv. 2021, 36, 492-494. [CrossRef]

21. Li, D.; Chen, Q.; Jia, Z.; Ke, J. A novel active power filter with fundamental magnetic flux compensation. IEEE Trans. Power Deliv. 2004, 19, 799-805. [CrossRef]

22. Sarkar, S.; Roy, A.; Purkayastha, B.S.; Sarkar, S.; Roy, A.; Purkayastha, B.S. Application of particle swarm optimization in data clustering: A survey. Int. J. Comput. Appl. 2013, 65, 38-46. 